\title{
Dual Right Coronary Artery Associated with ASD and Pulmonary Stenosis
}

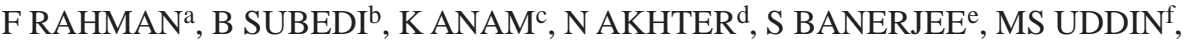 \\ ATM I HOSSAIN', C M AHMED ${ }^{\mathrm{h}}$, KMHS S HAQUE ${ }^{\mathrm{i}}$
}

(J Bangladesh Coll Phys Surg 2010; 28: 125-127)

\section{Introduction:}

Coronary artery anomalies occur in less than $1 \%$ of the cases undergoing coronary angiography, and constitute $1-2 \%$ of all congenital heart disease. ${ }^{1}$ The origin of the circumflex artery from the right coronary artery (RCA) or the right sinus of Valsalva is the most commonly encountered anomaly and is usually well tolerated ${ }^{2}$. We report the clinical, echocardiographic and

a. Fazlur Rahman, MD, D Card, MCPS, FACC, Assoc. Prof. (Interventional Cardiology), University Cardiac Center,Department of Cardiology, Bangabandhu Sheikh Mujib Medical University, Dhaka 1000, Bangladesh

b. Bikash Subedi MBBS, CCD,MPH, MD Cardiology, Final Part University Cardiac Center,Department of Cardiology, Bangabandhu Sheikh Mujib Medical University, Dhaka 1000, Bangladesh

c. Khairul Anam MD, Department of Cardiology, University Cardiac Center,Department of Cardiology, Bangabandhu Sheikh Mujib Medical University, Dhaka 1000, Bangladesh

d. N Akhter, FCPS,MS, Bangabandhu Sheikh Mujib Medical University, Dhaka 1000, Bangladesh

e. Sajal Banerjee, Professor of Cardiology, MD, FACC, University Cardiac Center,Department of Cardiology, Bangabandhu Sheikh Mujib Medical University, Dhaka 1000, Bangladesh

f. MS Uddin, MD,FACC, University Cardiac Center,Department of Cardiology, Bangabandhu Sheikh Mujib Medical University, Dhaka 1000, Bangladesh

g. ATM Iqbal Hossain, MD, FCPS, Ph D( Cardiology, Assoc Prof. Of Cardiology University Cardiac Center, Department of Cardiology, Bangabandhu Sheikh Mujib Medical University, Dhaka 1000, Bangladesh

h. CM Ahmed, MD, University Cardiac Center,Department of Cardiology, Bangabandhu Sheikh Mujib Medical University, Dhaka 1000, Bangladesh

i. KMHS Sirajul Haque, Professor and Chairman, University Cardiac Center,Department of Cardiology, Bangabandhu Sheikh Mujib Medical University, Dhaka 1000, Bangladesh

Address of Correspondence: Dr. Fazlur Rahman. MD. FACC, Room-201( 1st floor) D Block, BSMMU, Shahbag, Dhaka, Phone: 01715540407

Received: 13 August, 2008

Accepted: 7, August, 2009 angiographic findings of symptomatic 45 years elderly lady with the atrial septal defect and double right coronary artery and pulmonary stenosis. To our knowledge, such associated lesion as founding this case has not been reported in the literature till date at home and abroad.

\section{Case Report:}

A 45 years, non diabetic, non hypertensive lady presented with the palpitation for 2 years. The palpitation used to occur during exertion and relieved by rest and was associated with generalized fatigability. She has no history of chest pain, dizziness, dyspnoea, edema, features of hyperthyroidism, anxiety disorders. On general examination, her pulse was 88beats/min regular, Blood pressure 120/80 mm of $\mathrm{Hg}$, prominent a wave in JVP. Precordium examination revealed left parasternal lift, wide fixed splitting of second heart sound, ejection systolic murmur in the left upper sternal border best heard in inspiration. Other systemic examination was unremarkable. Our clinical diagnosis was ASD with Pulmonary stenosis.

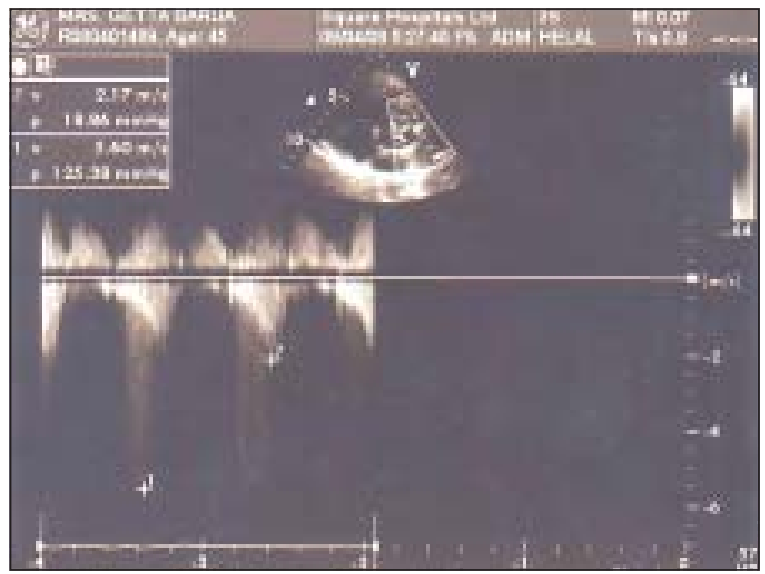

Fig.-1: Doppler Echocardiography of 45 years elderly lady showing increased pressure gradient across the pulmonary valve. 


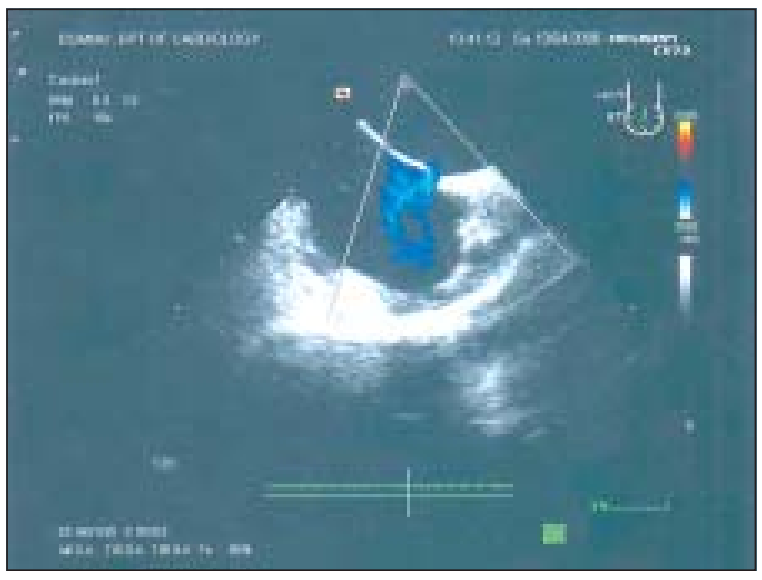

Fig.-2: Transoesophageal Echocardiography of the same lady showing atrial septal defect osteum secondum type.

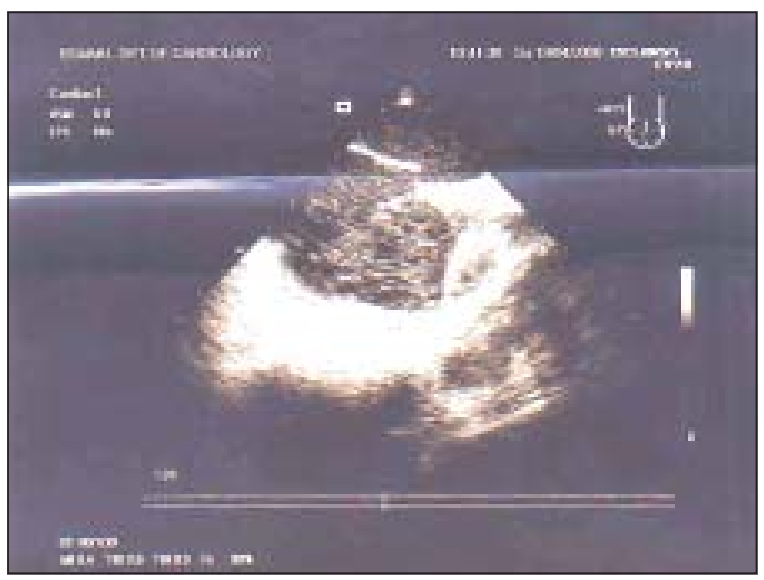

Fig.-3: Transesophageal echocardiography of the same lady showing passage of air bubble from $R A$ to $L A$ through atrial septal defect.

Her ECG showed right bundle branch block with right axis deviation and right ventricular hypertrophy. Transthoracic echocardiography showed dilated right atrium and right ventricle with right ventricular hypertrophy, pulmonary stenosis and pressure gradient of $125 \mathrm{~mm} \mathrm{Hg}$ across the pulmonary valve. Transesophageal echocardiography showed ostium secondum variety of atrial septal defect of $8.2 \mathrm{~mm}$ size and air bubble passed from right atrium to left atrium.

Subsequently she underwent right heart catheterization during which the catheter passed from right autrium to left autrium, significant step up of oxygen on oxymetry was noted in mid right autrium and. Her Qp:Qs ratio was 0.9.Coronary angiogram was also done and revealed normal left main ,LCx, LAD and 2 right coronary arteries with single normal anatomical osteum and both RCA with their branches are normal and disease free.

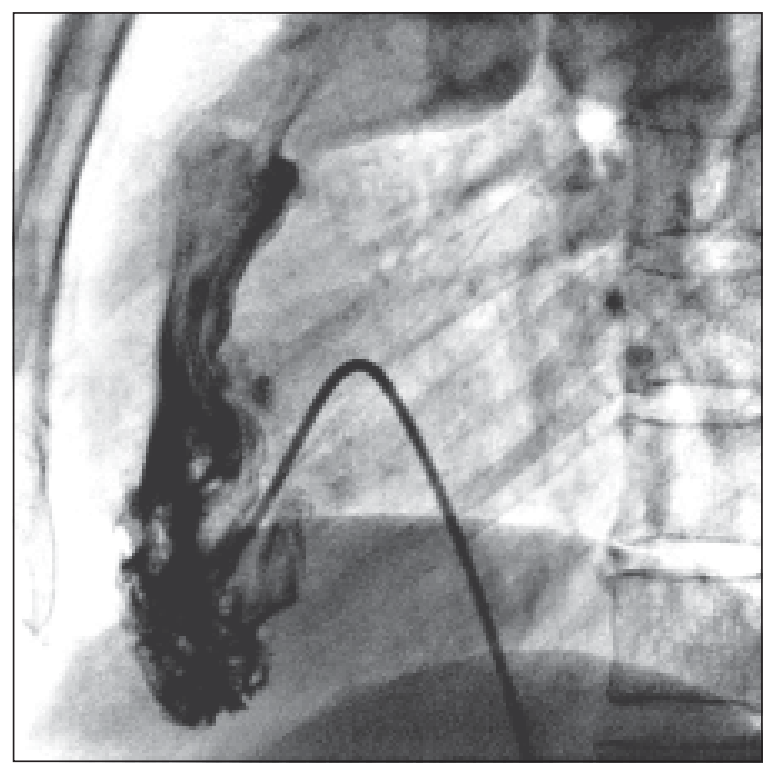

Fig.-4: Right vetriculography(Lateral View) of the same lady showing Pulmonary stenosis of infundibular and valvular type.

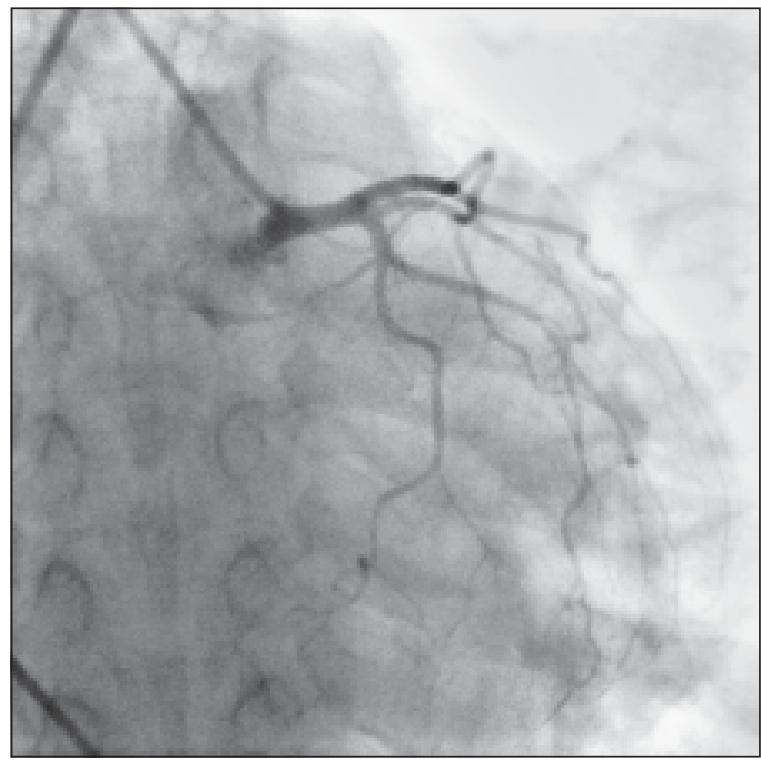

Fig.-5: Coronary angiography of the same lady showing normal left coronary arterial system. 


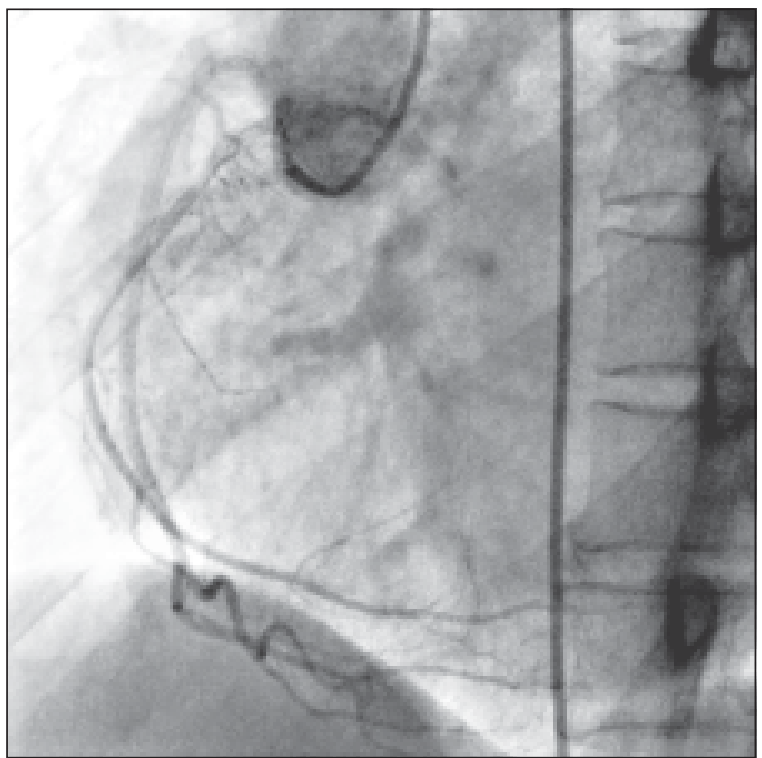

Fig.-6: Coronary angiogram of the same patient showing double right coronary arteries with single normal anatomical ostium. Just after the origin there is duplication and both the arteries with their branches are normal and disease free.

\section{Discussion:}

Coronary artery anomalies are encountered in less than $1 \%$ of the cases undergoing coronary angiography and in approximately $0.3 \%$ of autopsy series ${ }^{3-5}$. There is generally no gender difference in the incidence, and the most commonly encountered anomaly is the ectopic origin of coronary arteries ${ }^{4}$.

The duplication of the RCA is extremely uncommon, and up to now, only nine cases have been reported ${ }^{6}$. Duplication of coronary arteries is accepted as a benign pathology. In RCA duplication, each artery may arise from a separate ostium or from the main trunk during the initial course of the RCA, and generally runs parallel, or one of them may course towards the anterolateral surface of the right ventricle. Coexistence of premature atherosclerosis as a result of altered blood flow kinetics has been a controversial issue ${ }^{7,8}$.Among the previously reported cases of double RCA, there were only two patients with coexistent anomalies ${ }^{[9,10]}$ and one patient with atherosclerosis ${ }^{11}$. Serkan $\mathrm{T}$ et al reported a case of ventricular septal defect and double right coronary artery originating from the left main coronary artery and the right coronary sinus ${ }^{12}$. In our case, there are two right coronary arteries with origin from the same osteum and are disease free.This anomaly is associated with ASD ostium secondum type and pulmonary stenosis. Such interesting coronary artery anomaly associated with other congenital heart disease, to our knowledge, is the first reported case in the world.

\section{Conclusion:}

Dual Coronary artery anomalies associated with other congenital heart disease is a rare condition. One should be cautious to evaluate such a patient during invasive and non invasive diagnostic procedures for proper management of such patient.

\section{References:}

1. Harikrishnan S, Jacob SP, Tharakan J, Titus T, Kumar VK, Bhat A, et al. Congenital coronary anomalies of origin and distribution in adults: a coronary arteriographic study. Indian Heart J 2002;54:271-5.

2. Ueyama K, Ramchandani M, Beall AC Jr, Jones JW. Diagnosis and operation for anomalous circumflex coronary artery. Ann Thorac Surg 1997;63:377-381.

3. Jureidini SB, Marino CJ, Rao PS. Congenital coronary artery abnormalities. Indian J Pediatr 1998;65:217-29.

4. Yamanaka O, Hobbs RE. Coronary artery anomalies in 126,595 patients undergoing coronary arteriography. Cathet Cardiovasc Diagn 1990;21:28-40.

5. Taylor AJ, Rogan KM, Virmani R. Sudden cardiac death associated with isolated congenital coronary artery anomalies. J Am Coll Cardiol 1992;20:640-7.

6. Erbagci H, Davutoglu V, Turkmen S, Kizilkan N, Gumusburun E. Double right coronary artery: review of literature. Int J Cardiovasc Imaging 2006;22:9-11.

7. Topaz O, DeMarchena EJ, Perin E, Sommer LS, Mallon SM, Chahine RA. Anomalous coronary arteries: angiographic findings in 80 patients. Int J Cardiol 1992;34:129-38.

8. Click RL, Holmes DR Jr, Vlietstra RE, Kosinski AS, Kronmal RA. Anomalous coronary arteries: location, degree of atherosclerosis and effect on survival-a report from the Coronary Artery Surgery Study. J Am Coll Cardiol 1989;13:531-7.

9. Young-Hyman PJ, Tommaso CL, Singleton RT. A new double coronary artery anomaly: the right coronary artery originating above the coronary sinus giving off the circumflex artery. J Am Coll Cardiol 1984;4:1329-31.

10. Garg N, Tewari S, Kapoor A, Gupta DK, Sinha N. Primary congenital anomalies of the coronary arteries: a coronary: arteriographic study. Int J Cardiol 2000;74:39-46.

11. Timurkaynak T, Ciftci H, Cengel A. Double right coronary artery with atherosclerosis: a rare coronary artery anomaly. J Invasive Cardiol 2002;14:337-9.

12 Serkan T et al. Double Right Coronary Artery Arising From the Left Main Stem and Right Coronary Sinus Associated with Ventricular Septal Defect in an Adult: An Extremely Rare Case. Heart, Lung and Circulation:16:4: 2007, 318-321. 